\section{High-contrast imaging (FICE) improves visualization of gastrointestinal vascular ectasias}
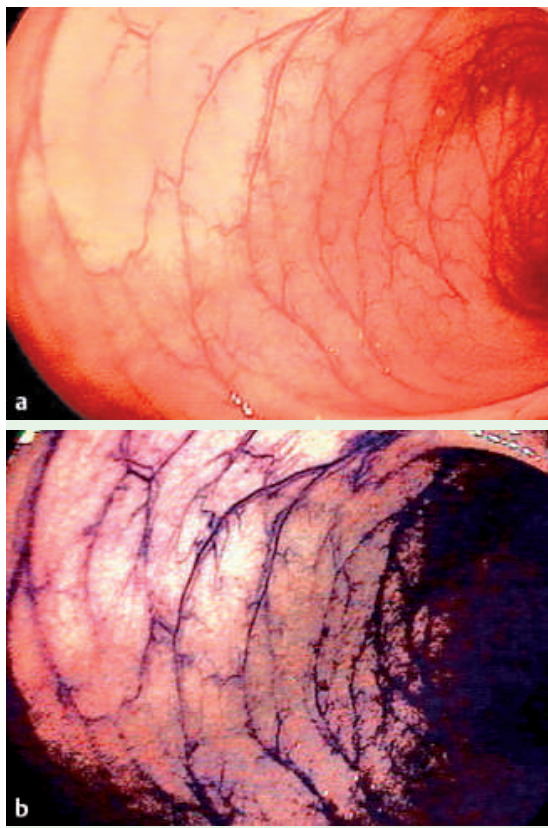

Fig. 1 a Blood vessels in normal colon. b Same area of colon with FICE ${ }^{\mathrm{TM}}$ preset 4, displaying vessels with high contrast.

Vascular ectasia or arteriovenous malformations account for about $5 \%-10 \%$ of upper and nearly $30 \%$ of lower gastrointestinal bleeding, but can sometimes be difficult to detect during endoscopy [13]. High-contrast imaging is useful in displaying microvasculature in neoplasia $[4,5]$. We used the Fujinon Intelligent Color Enhancement (FICE ${ }^{\mathrm{TM}}$ ) system, (Fujinon, Inc. Wayne, New Jersey, USA), and noted the ease with which gastrointestinal blood vessels could be displayed at preset 4 ( $\bullet$ Fig. 1$)$.

A 63-year-old man with gastrointestinal bleeding underwent upper endoscopy, where active bleeding was seen to emanate from the gastric body ( $\bullet$ Fig. 2 a). On washing, no underlying lesion was seen, but with FICE (preset 4) a prominent vascular ectasia was displayed at the point of observed bleeding that was not visible on switching back to normal imaging ( Fig. 2b). A 54-year-old man with intermittent lower gastrointestinal bleeding had a few non-bleeding vascular ectasias seen in the ascending colon during colonoscopy; one prominent vascular ectasia was barely visible with white
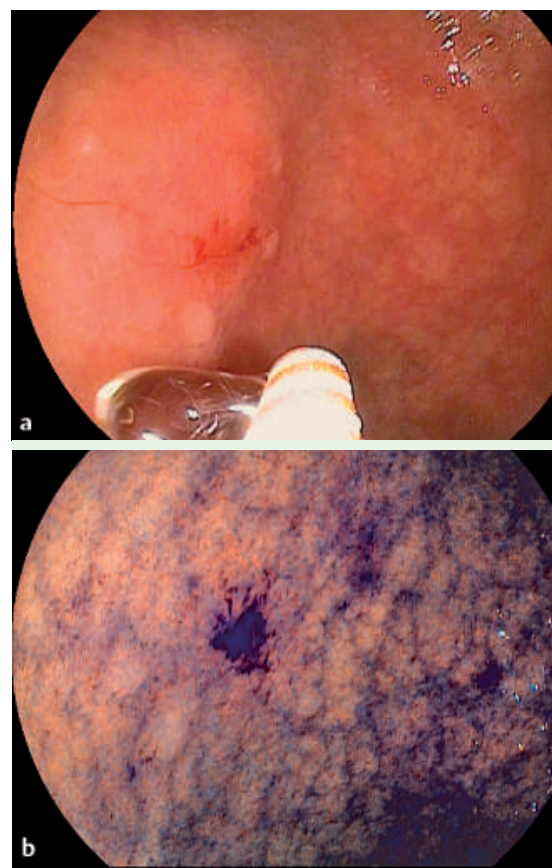

Fig. 2 a Active bleeding in gastric body, immediately after washing, without any underlying lesion. The tip of a gold probe catheter is visible. $\mathbf{b}$ A prominent vascular ectasia is seen at the same site with FICE preset 4.

light, but was clearly seen with FICE (๑ Fig. 3).

These examples illustrate the ability of FICE to enhance the appearance of normal vessels ( $\bullet$ Fig. 1 ) and poorly visible or unseen vascular ectasia ( $\bullet$ Fig. 2 and 3). With FICE, white light is used to illuminate the mucosa, but three wavelengths (at preset $4: 405 \mathrm{~nm}, 500 \mathrm{~nm}$, and $520 \mathrm{~nm}$ ) are selected from the reflected light to produce an image with high contrast, with the vessels appearing much darker than the surrounding mucosa. The visibility of vascular ectasias depends on their size, hydration, hemoglobin level, blood flow, and use of narcotic drugs [2,3]. High-contrast imaging not only improves the visibility of normal mucosal vessels, but may aid in the detection of vascular ectasias that are not easily seen.

Endoscopy_UCTN_Code_CCL_1AB_2AD_3AZ Endoscopy_UCTN_Code_CCL_1AD_2AF

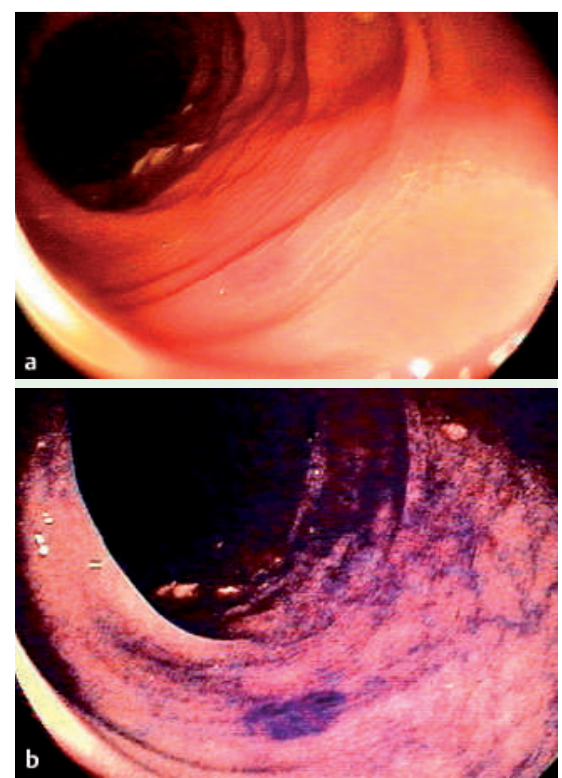

Fig. 3 a Faint red area in the ascending colon, seen when advancing the endoscope. $\mathbf{b}$ A vascular ectasia is displayed at the same site by FICE preset 4.

\section{A. Ringold, S. Sikka, B. Banerjee}

Division of Gastroenterology, Department of Medicine, Washington University School of Medicine, and St. Louis VA Medical Center, St. Louis, Missouri, USA

\section{References}

1 Zuckerman GR, Cornette GL, Clouse RE et al. Angiodysplasia as a cause of upper gastrointestinal bleeding. Arch Intern Med 1985; 45: $458-461$

2 Boley SJ, Brandt LJ. Vascular Ectasias of the colon-1986. Dig Dis Sci 1986; 31: S26-S45

3 Brandt LJ, Spinnell MK. Ability of naloxone to enhance the colonoscopic appearance of normal colon vasculature and colon vascular ectasias. Gastrointest Endosc 1999; 49: 79-83

4 Muto M, Katada C, Sano Yet al. Narrow band imaging: a new diagnostic approach to visualize angiogenesis in superficial neoplasia. Clin Gastroenterol Hepatol 2005; 3: S16S20

5 Nakayoshi T, Tajiri K, Matsuda Ket al. Magnifying endoscopy combined with narrow band imaging system for early gastric cancer: correlation of vascular pattern with histopathology. Endoscopy 2004; 36: $1080-1084$

Bibliography

DOI $10.1055 / \mathrm{s}-2007-966963$

Endoscopy 2008; 40: E26

(c) Georg Thieme Verlag KG Stuttgart · New York . ISSN 0013-726X

\section{Corresponding author}

\section{B. Banerjee, MD}

Division of Gastroenterology

Washington University School of Medicine 660, South Euclid Avenue, Campus Box 8124 St. Louis, MO 63110, USA, Fax: +1-314-454-8289 bbanerje@im.wustl.edu 